6-2007

\title{
Modeling and Performance Evaluation of Machining Spindle with Active Magnetic Bearings
}

Jerzy T. Sawicki

Cleveland State University, j.sawicki@csuohio.edu

Eric H. Maslen

University of Virginia

Kenneth R. Bischof

Federal-Mogul Corporation

Follow this and additional works at: https://engagedscholarship.csuohio.edu/enme_facpub

Part of the Mechanical Engineering Commons

How does access to this work benefit you? Let us know!

Publisher's Statement

The final publication is available at Springer via http://dx.doi.org/10.1007/BF03027055

\section{Original Citation}

Sawicki, J. T., Maslen, E. H., and Bischof, K. R., 2007, "Modeling and Performance Evaluation of Machining Spindle with Active Magnetic Bearings," Journal of Mechanical Science and Technology, 21(6) pp.

847-850.

This Article is brought to you for free and open access by the Mechanical Engineering Department at EngagedScholarship@CSU. It has been accepted for inclusion in Mechanical Engineering Faculty Publications by an authorized administrator of EngagedScholarship@CSU. For more information, please contact library.es@csuohio.edu. 


\title{
Modeling and Performance Evaluation of Machining Spindle with Active Magnetic Bearings
}

\author{
Jerzy T. Sawicki ${ }^{\mathrm{a},}$, , Eric H. Maslen ${ }^{\mathrm{b}}$, Kenneth R. Bischof ${ }^{\mathrm{c}}$ \\ ${ }^{a}$ Department of Mechanical Engineering, Center for Rotating Machinery Dynamic \& Control, Cleveland State University \\ ${ }^{\mathrm{b}}$ University of Virginia \\ ${ }^{\circ}$ Federal-Mogul Corporation, U.S.A.
}

\begin{abstract}
Active magnetic bearings (AMBs) are increasingly employed in the machine tool industry to exploit their advantages over classical bearings such as high speed capability, rotation accuracy, high stiffness, and accurate displacement tracking capability. Furthermore, the possibility of on-line monitoring of the machining process (e.g., cutting force measurement, tool wear) makes AMB spindles very appealing to the High-Speed Machining (HSM) industry. Despite significant progress already reached in HSM technology, there remain numerous open challenges in modeling and control of magnetic bearings as applied to machining spindles. These include optimum control given AMB magnetic saturation levels, management of nonlinear effects, reduction of chatter, and rotor properties. This paper describes a five-degree-of-freedom, high-speed machining spindle supported on AMBs. The rotordynamic modeling and experimentally extracted transfer functions are presented and analyzed. The experimentally measured tool tip compliance is used to compare PID and mu-synthesis control schemes. The primary finding is that the achieved tool tip stiffness is substantially higher with the $\mu$-synthesized controllers than with the best PID we were able to design.
\end{abstract}

Keywords: Active magnetic bearing; Machining spindle; High-speed machining; $\mu$-synthesis

\section{Introduction}

As the application of High Speed Machining (HSM) in production environments grows, interest in the AMB machining spindles also increases (e.g., Siegwart et al., 1990 ; Fittro et al., 1997 ; Fittro and Knospe, 1998). AMBs permit a higher bearing surface speed and larger diameter, or stiffer, spindle rotors. In addition, active control capabilities enable greater spindle damping and the active suppression of chatter (Fittro and Knospe, 1998).

However, to ensure high-quality machining operation, the advanced control strategies require an accurate mathematical model for the spindle, its compo-

\footnotetext{
${ }^{7}$ Corresponding author. Tel.: +216 687 2565, Fax.: +216 6879280

E-mail address: j.sawicki@esuohio.edu
}

nents, as well as for the cutting dynamics. This paper presents a modeling approach for a high-speed spindle-bearing system based on finite-element analysis coupled with experimental modal identification and compares the performance of controllers synthesized with the resulting model.

\section{AMB spindle and model}

The platform for this study is an AMB supported machine tool spindle with the cross section shown in Fig. 1. The spindle was originally developed by Revolve Magnetic Bearings, a subsidiary of SKF, Inc., and adapted to permit control using a dSPACE digital controller. The spindle rotor is supported by two radial bearings and one thrust bearing. The maximum static radial load capacities are appro- 


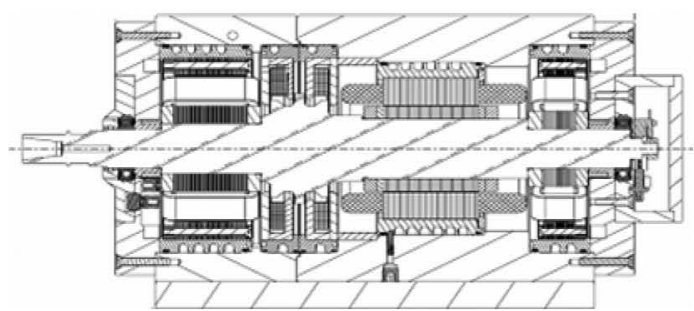

Fig. 1. Cross section of AMB machining spindle without tool holder.

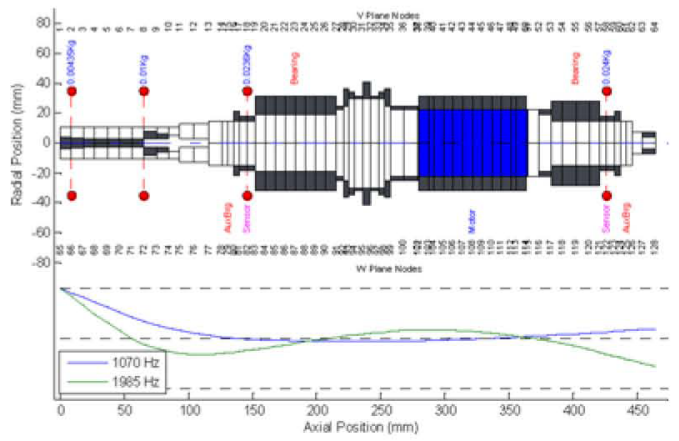

Fig. 2. Finite element model and first two bending modes of free-free rotor with tool holder.

ximately 1400 and $600 \mathrm{~N}$ for the front and rear bearings, respectively, and the maximum axial capacity for thrust bearing is $500 \mathrm{~N}$. The spindle reaches a rotational speed of $50,000 \mathrm{rpm}$ at $10 \mathrm{~kW}$. The $\mathrm{AC}$ motor acts on the rotor between the thrust and rear radial bearing.

A free-free rotor model was constructed using a Timoshenko beam element formulation containing 64 elements. Proportional damping and linear gyroscopic effects were assumed. The large rotor model was then reduced using modal reduction to four principal modes, including the two rigid body modes. Figure 2 shows the rotor finite element model and the first two bending modes.

A PID controller was designed to perform a system identification of the levitated spindle to experimentally determine the closed-loop transfer function between current disturbance and rotor response. The modeled Bode plot for the controller implemented at $10 \mathrm{kHz}$ is shown in the left column of Fig. 3. With the levitating controller operating, a sine sweep current signal (0.25 Ampere over a 0 to $2500 \mathrm{~Hz}$ frequency bandwidth) was injected to each axis at a time and closed-loop performance was extracted. The right column of Fig. 3 illustrates the results of such measurement when the current perturbation and measurement are taken for the same axis at the front bearing. A linearized AMB
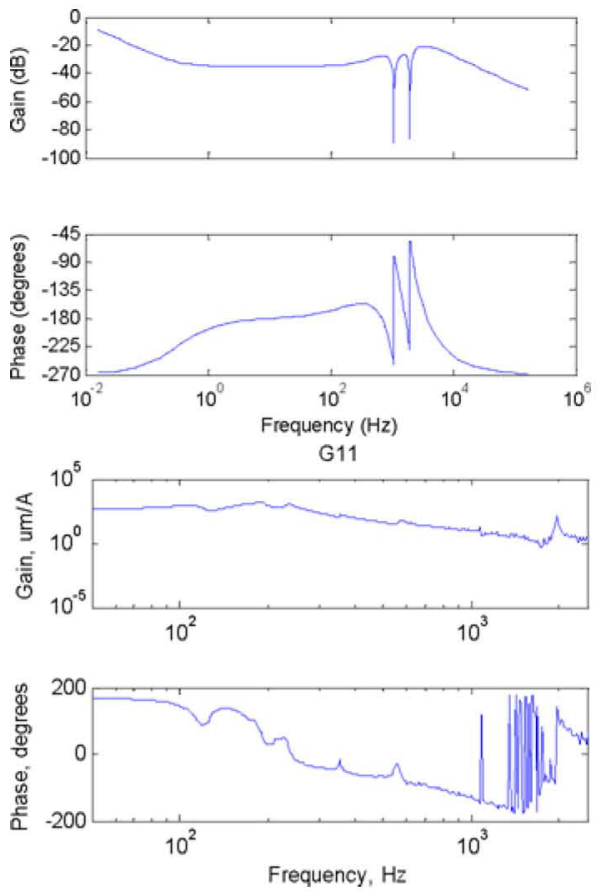

Fig. 3. Modeled transfer function of PID controller (left column) and experimentally extracted closed-loop transfer function of system (right column).
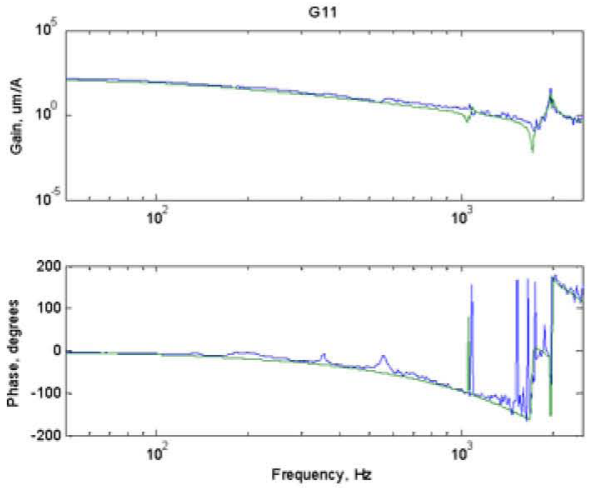

G21
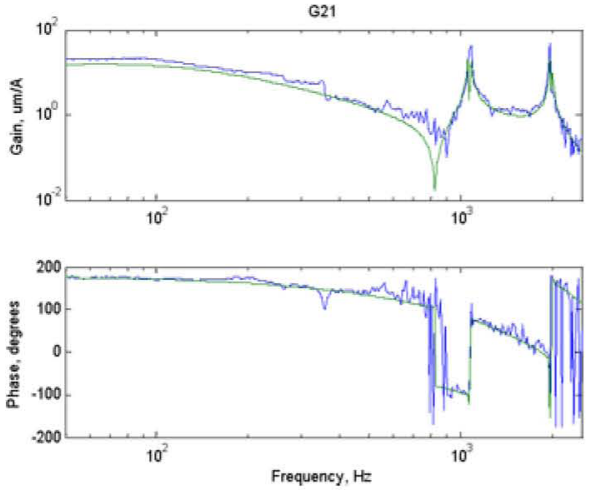

Fig. 4. Comparison of the modeled and experimentally extracted open loop transfer function of the plant. 
$\mathrm{m} o \mathrm{~d}$ e 1 w a $\mathrm{s}$ e $\mathrm{m}$ p 1 o $y$ e $\mathrm{d}$, and the parameters of the AMB were obtained from the analytical model and subsequently refined using the closed-loop testing data.

The controller was implemented using dSPACE based on differential control, with 10 output channels required and provided by the two D/A boards. The hardware consisted of the DS1005 PPC Board featuring the PowerPC $750 \mathrm{GX}$ running at $1 \mathrm{Ghz}$. The controller sampling time was $10 \mathrm{kHz}$. Figure 4 presents comparison of the two components of the open loop plant transfer function extracted experimentally and the plant model with the amplifier bandwidth set to $2475 \mathrm{~Hz}$ and the sample delay set to 170 microseconds. The first bending mode at 1970 $\mathrm{Hz}$ is nearly indistinguishable in a plot of $\mathrm{G}_{11}$ due to the presence of a node for the first mode that is very close to the sensor location.

It should be noted that the above open loop transfer function for the plant measurement were obtained by accounting simultaneously for all inputs to the system (all of the differential currents) and all of the outputs from the system. For each conducted experiment, a vector of all inputs to the plant and a vector of all outputs from the plant were recorded.

\section{3. $\mu$-synthesis based controller}

$\mu$-synthesis is a model-based controller design technique requiring an accurate mathematical model of the plant dynamics and bounds on the uncertainties associated with that model (Doyle, 1982 ; Zhou and Doyle, 1998). This design methodology, focused on achieving guaranteed stability and performance for uncertain systems, can be very effective for machining application, due to the presence of variation of cutting forces, feed rates, and various cutting conditions.

Several $\mu$-controllers were designed and just two examples are illustrated in Fig. 5, where one of the controllers was optimized to achieve the best machining performance in terms of high surface finish quality. Both controllers were implemented as discrete time, state-space systems with a sampling rate of $10 \mathrm{kHz}$. For each case the MATLAB ${ }^{\mathrm{TM}}$ Robust Control Toolbox was used to synthesize robust controller via $\mu$-synthesis D-K iteration. The resulting optimized controller was $88^{\text {th }}$ order and was reduced to $44^{\text {th }}$ order by model order reduction using Hankel singular value based algorithms. The
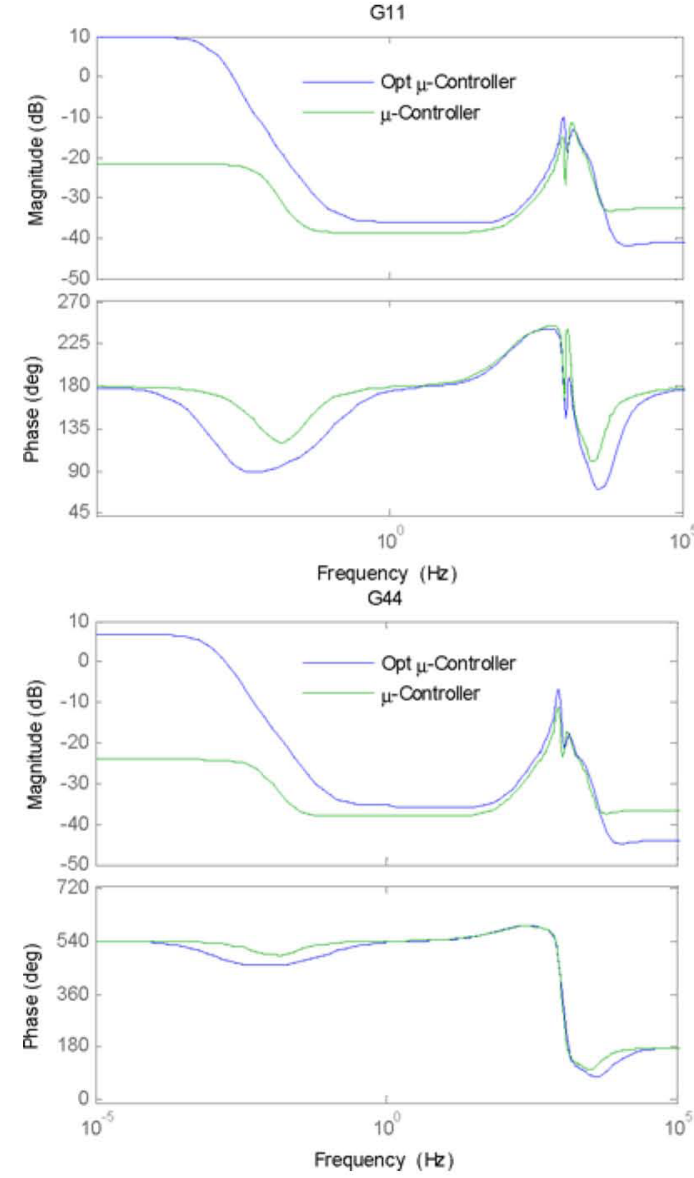

Fig. 5. Comparison of two $\mu$-controllers; one is optimized for machining.

controller successfully supported rotor over its entire speed range, i.e., to its maximum speed of 50,000 rpm The uncertainties in actuator gain and bearing negative stiffness were modeled as $3 \%$ and $15 \%$ real uncertainties of nominal value, respectively. In addition, the modal frequencies of the first and second modes were modeled as $1 \%$ complex uncertainty of nominal value for each mode. These latter uncertainties discourage the synthesis machinery from introducing controller dynamics that precisely cancel the dynamics associated with these modes as, for instance, very sharp notch filters.

To determine the spindle stiffness at the tool tip, with the rotor supported on each the PID, the $\mu$ controller, and the optimized $\mu$-controller, impact testing was carried out with an instrumented hammer. The results presented in left column of Fig. 6 show the advantage of $\mu$-controllers, especially in the vicinity of the first and second modes, where PID sti- 

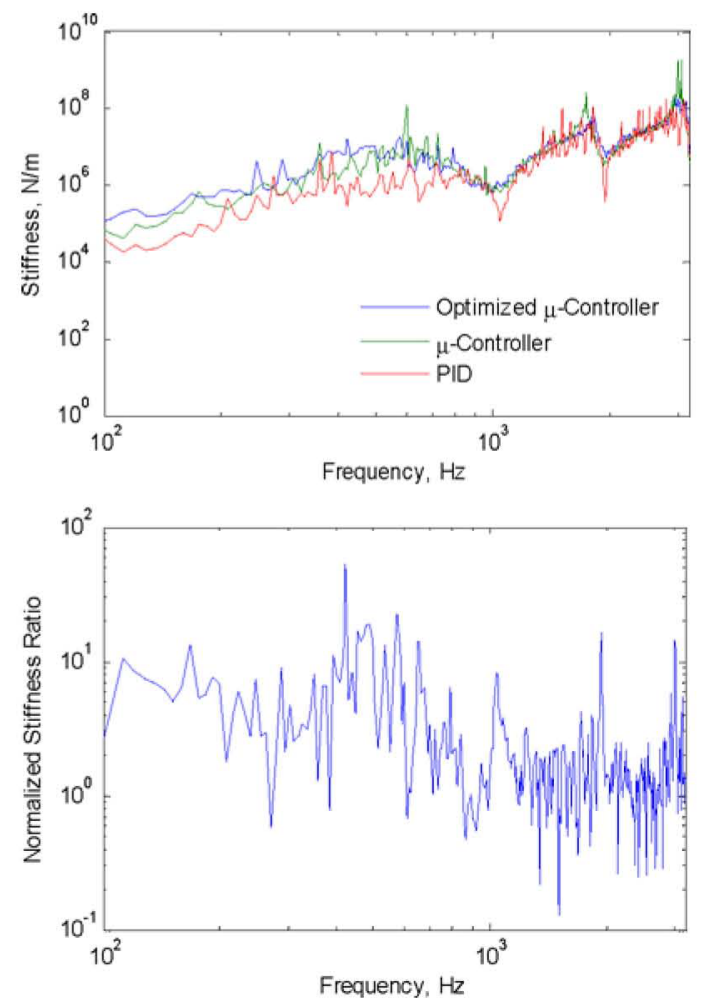

Fig. 6. Stiffness of the spindle at the tool tip extracted from the hammer test for PID and $\mu$-controllers (left column); normalized with respect to PID stiffness for optimized $\mu$ controller (right column).

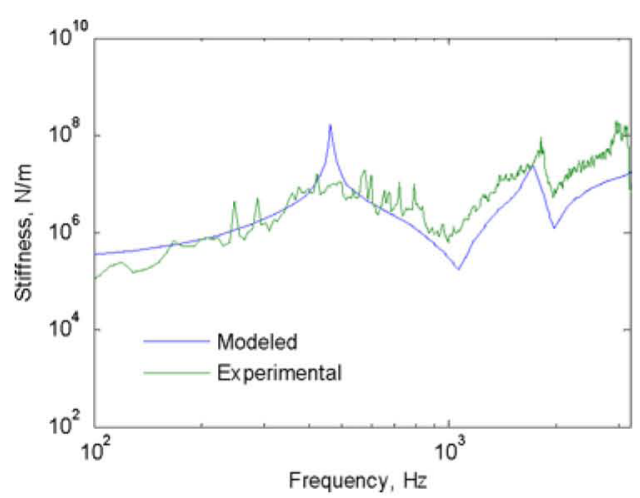

Fig. 7. Comparison of modeled and experimental spindle stiffness at the tool tip for the optimized $\mu$-controller.

ffness is significantly lower. Over the wide range of frequencies the PID controller is much less stiff while the optimized $\mu$-controller provides the highest stiffness support. This is illustrated on the spindle stiffness at the tool tip plot for the optimized $\mu$-controller normalized with respect to the stiffness of the corresponding PID controller, as shown in the right column of Fig. 6. For the frequencies lower than 1 $\mathrm{kHz}$ the optimized $\mu$-controller achieves more than twice higher stiffness than the tuned PID controller

Figure 7 shows the comparison of stiffness results obtained theoretically and experimentally for the optimized $\mu$-controller. It is clear that the model agrees well with the experimental data.

\section{Conclusions}

The presented simulation and experimental results show the potential of $\mu$-synthesized control of AMB machining spindles for improved cutting performance. Particularly, the strong advantage of $\mu$ controllers over PID controller is found for the spindle stiffness control at the cutting tool.

\section{References}

Doyle, J. C., 1982, “Analysis of Feedback Systems with Structured Uncertainties," IEE Proceedings, Part D, Vol. 129, pp. 242 250.

Fittro, R., Hammond, R., Allaire, P. and Maslen, E., 1997, "Initial Controller Design of a Magnetic Bearing Supported Prototype Textile Spindle," Proceedings of MAG '97 Industrial Conference and Exhibition on Magnetic Bearings, Alexandria, VA, pp. 57 65.

Fittro, R. L. and Knospe, C. R., 1998, “ $\mu$-Synthesis Control Design Applied to a High Speed Machining Spindle With Active Magnetic Bearings," oth International Symposium on Magnetic Bearings, MA, USA, pp. 449-458.

Li, G., Wang, Q. and Maslen, E., 2004, “A Case Study in Evaluation of the Stability Margin of an AMB Rotor Using $\mu$ - and PID Controllers," Conference on Standardization for AMB Rotor, NEDO-ISO Joint Workshop, Ibaraki, Japan.

Siegwart, R., Larsonneur, R. and Traxler, A., 1990, "Design and Performance of a High Speed Milling Spindle in Digitally Controlled Active Magnetic Bearings," $2^{\text {nd }}$ International Symposium on Magnetic Bearings, Tokyo, Japan, pp. 197 204.

Zhou, K. and Doyle, J. C., 1998, Essentials of Robust Control, Prentice-Hall, Upper Saddle River, NJ, 1998. 